\title{
Penatalaksanaan Oligodontia pada Anak 14 Tahun dengan Sindrom Ectodermal Dysplasia: Laporan Kasus
}

\author{
Anie Apriani, ${ }^{1}$ Inne Suherna Sasmita ${ }^{2}$ \\ ${ }^{1}$ Peserta PPDGS Kedokteran Gigi Anak Fakultas Kedokteran Gigi Universitas Padjadjaran \\ ${ }^{2}$ Staf Pengajar Departemen Kedokteran Gigi Anak Fakultas Kedokteran Gigi Universitas Padjadjaran
}

\begin{abstract}
Abstrak
Ectodermal dysplasia adalah kelainan herediter yang jarang didapatkan, lebih kurang 7.000 kasus di dunia. Pada kelainan ini terjadi gangguan perkembangan struktur organ-organ yang berasal dari lapisan ektodermal seperti rambut, gigi, kuku, dan kelenjar keringat. Dilaporkan kasus sindrom ectodermal dysplasia pada seorang anak perempuan berusia 14 tahun dengan manifestasi klinis berupa oligodontia (kehilangan gigi lebih dari 6 gigi pada rahang atas dan bawah), rambut tipis dan keriting, abnormalitas bentuk kuku kaki, dan gangguan ekskresi keringat. Tujuan perawatan pasien ini adalah mendapatkan fungsi estetik dan pengunyahan pasien yang terganggu akibat tidak terdapat benih gigi permanen, selain itu juga untuk menjaga supaya pertumbuhan rahang tetap berkembang normal. Penatalaksanaan oligodontia berupa pembuatan gigi tiruan lepasan dan mahkota akrilik pada seluruh gigi anterior rahang atas dan bawah. Simpulan yang didapatkan pada pasien ini adalah tercapainya perbaikan estetika dan pengembalian fungsi pengunyahan serta pemeliharaan pertumbuhan rahang dapat terjaga dengan baik. [MKB. 2015;47(4):255-60]
\end{abstract}

Kata kunci: Ectodermal dysplasia, gigi tiruan, oligodontia

\section{Oligodontia Management in Children 14 Years with Ectodermal Dysplasia Syndrome: Case Report}

\begin{abstract}
Ectodermal dysplasia is a hereditary disorder that is rarely seen with approximately 7000 cases in the world. In this disorder, Ectodermal dysplasia occurs as a developmental disorder of organ structures derived from the ectodermal layer such as hair, teeth, nails, and sweat glands. This is a case report of ectodermal dysplasia in a 14-year-old girl with clinical manifestations of oligodontia (tooth loss, more than 6 teeth on the upper and lower jaw), thin and curly hair, abnormal toenail shape, and impaired excretion of sweat. The purpose of the treatment was to make the patient regains her esthetic and masticatory functions, which were disrupted by the absence of permanent tooth buds, as well as to maintain the normal growth of the developing jaws. Treatment for the patient's with oligodontia included the use of removable denture in lower jaw and application of acrylic crowns on all upper and lower anterior teeth resulting in improved esthetics and masticatory function. It is concluded that the treatment has been able to improve the esthetics and to return the masticatory function of the patient while maintaining the normal growth of the jaws. [MKB. 2015;47(4):255-60]
\end{abstract}

Key words: Ectodermal dysplasia, oligodontia, prothes

Korespondensi: Anie Apriani, drg, Fakultas Kedokteran Gigi Universitas Padjadjaran Bandung, Jl. Sekeloa No. 2 Bandung, mobile 08164872941, e-mail anie_apriani79@yahoo.com 


\section{Pendahuluan}

Ectodermal dysplasia atau ED merupakan suatu kelainan heterogen yang diwariskan ditandai dengan terganggunya perkembangan jaringan ektodermal (terutama rambut, kuku, gigi dan kulit) dan kadang-kadang dapat juga berasal dari jaringan mesodermal. ${ }^{1} \mathrm{ED}$ merupakan gangguan yang relatif jarang, dengan frekuensi kejadian bervariasi antara 1:10.000 dan juga 1:100.000 kelahiran hidup dan lebih sering pada laki-laki. ${ }^{2}$ Kelainan ED merupakan kelainan herediter yang berbentuk dominan autosomal maupun resesif $X$-linked. ${ }^{3}$ Pada perempuan lebih jarang terjadi karena ketika mutasi gen pada kromosom $X$ yang menyebabkan masalah, biasanya akan jauh lebih jelas pada laki-laki daripada perempuan. Hal ini karena laki-laki hanya memiliki satu salinan dari setiap gen pada kromosom X, sedangkan seorang perempuan memiliki dua salinan. ${ }^{4}$

Salah satu tipe ED yang sering ditemukan adalah tipe resesif $X$-linked hipohidrosis. ${ }^{5}$ Pasien dengan ED tidak memiliki atau memiliki sedikit kelenjar keringat yang mampu mengakibatkan pengurangan jumlah produksi kelenjar keringat sehingga kulit tidak mampu mengontrol suhu dengan benar. Kulit akan terlihat tipis di bawah pencahayaan. Rambut dapat tidak ada/sangat tipis. Setelah pubertas pertumbuhan rambut meningkat pada beberapa pasien. Alis, bulu mata, dan rambut tubuh lainnya mungkin juga tidak ada atau jarang. Kuku terutama kuku pada jari kaki umumnya kurang berkembang dan kecil, kadang tebal atau tipis, rapuh, berubah warna, retak, dan/atau bergerigi. ${ }^{6}$

Manifestasi intraoral yang terdapat pada kasus tersebut adalah oligodontia, yaitu berupa kelainan jumlah gigi, berupa tidak terdapat gigi permanen lebih dari enam, baik pada rahang atas/bawah. ${ }^{7}$ Rehabilitasi prostetik pada anak dengan sindrom ED bergantung pada tingkat anodontia (tidak terdapat gigi). Perawatan anodontia berupa pembuatan gigi palsu lengkap, baik konvensional atau implan. Pada pasien oligodontia, pembuatan gigi palsu lepasan atau gigi palsu parsial tetap dan overdentures dapat dilakukan. ${ }^{8}$

Pada kasus ini, kami melaporkan perawatan oligodontia memakai mahkota akrilik untuk gigi anterior rahang atas dan bawah serta pembuatan gigi tiruan lepasan untuk rahang bawah untuk pasien anak dengan sindrom ED, dengan tujuan memperbaiki estetika dan fungsi pengunyahan serta pemeliharaan pertumbuhan rahang pasien.

\section{Laporan Kasus}

Seorang anak perempuan berusia 14 tahun dirujuk ke klinik Pedodonti Rumah Sakit Gigi dan Mulut Fakultas Kedokteran Gigi Universitas Padjadjaran (Unpad) Bandung dengan diagnosis oligodontia gigi permanen. Keluhan pasien berupa penampilan yang kurang baik karena gigi geligi kecil dan jarang serta fungsi pengunyahan yang kurang baik. Pasien ini memiliki riwayat kelainan di dalam pertumbuhan rambut yang tumbuh sangat lambat dan juga keriting. Pasien jarang berkeringat dan kulit terutama di tungkai bawah tampak kering. Ditemukan juga kuku kaki yang kecil dan bergerigi. (Gambar 1). Pada pasien tidak terdapat gangguan pertumbuhan (BB/TB: $35 \mathrm{~kg} / 147,5 \mathrm{~cm}$ ), kelainan sistemik, serta gangguan mental dan intektual.

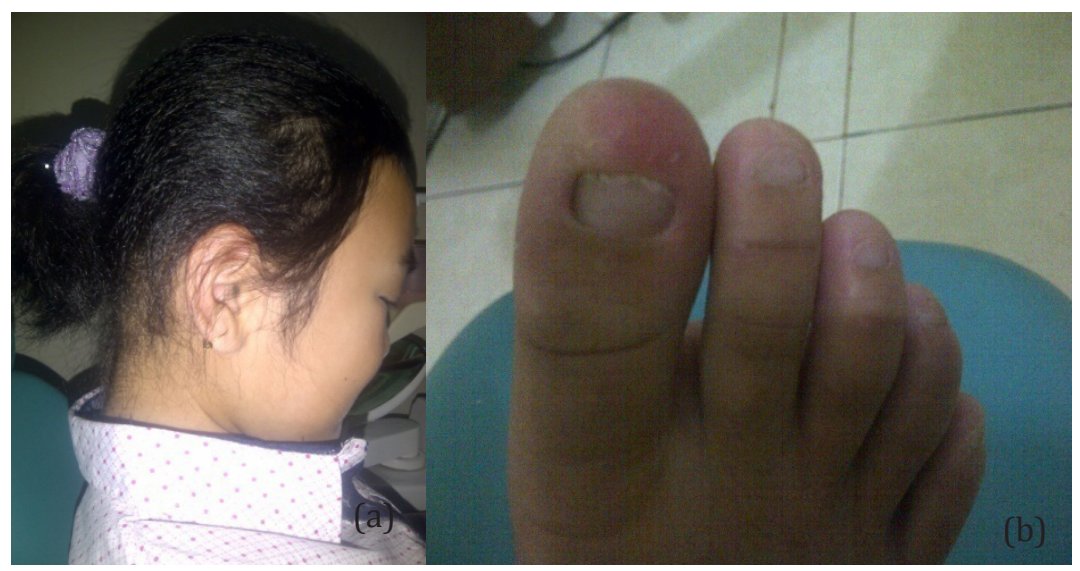

Gambar 1 Gambaran Klinis Ekstraoral

Keterangan: (a) rambut yang tipis dan keriting, (b) kuku kaki bergerigi 


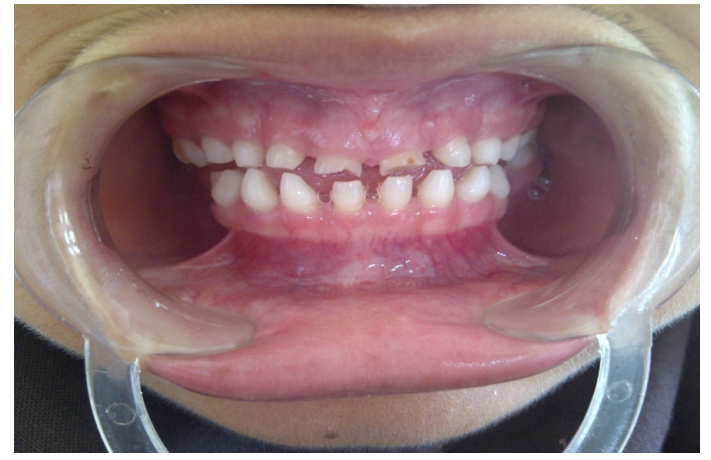

Gambar 2 Gambaran Intraoral Sebelum Perawatan

Pemeriksaan intraoral terdapat jumlah saliva yang sedikit, gigi sulung berbentuk conus pada gigi $53,52,62,63,73,72,71,81,82,83$ disertai diastema masing-masing yaitu sebesar $2,5 \mathrm{~mm}$. Pulpitis reversibel gigi 65,74 , dan 84 . Gigi 75 dan 85 telah lepas. Jaringan mukosa dan gingiva sekitarnya dalam batas normal, higiene oral baik (Gambar 2).

Foto panoramik tampak gigi geligi sulung dengan akar yang tidak teresorbsi, tidak ada benih gigi permanen kecuali pada gigi 16 (belum erupsi) dan gigi 36 sudah erupsi (Gambar 3).

Pada pasien ini tidak didapatkan riwayat prematuritas dan juga BBLR. Selama kehamilan ibu pasien tidak mempunyai riwayat meminum obat-obatan tertentu di luar obat yang biasa dikomsumsi pada kehamilan. Erupsi gigi sulung pertama kali usia 10 bulan gigi anterior rahang bawah. Riwayat keluarga didapatkan keluarga dari pihak ayah mempunyai gigi geligi dengan bentuk yang kecil. Pemeriksaan klinis dan juga riwayat keluarga menegakkan diagnosis sindrom ectodermal dysplasia. ${ }^{9}$

Rencana perawatan yang akan dilakukan berupa preventif, restoratif, serta rehabilitatif. Perawatan preventif antara lain berupa dental

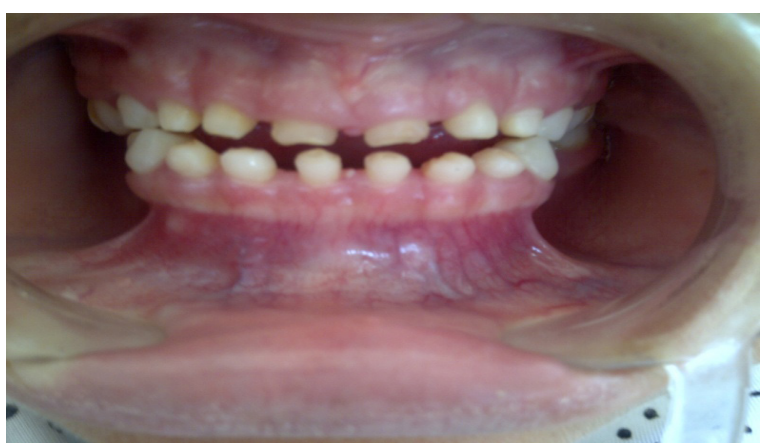

Gambar 4 Preparasi

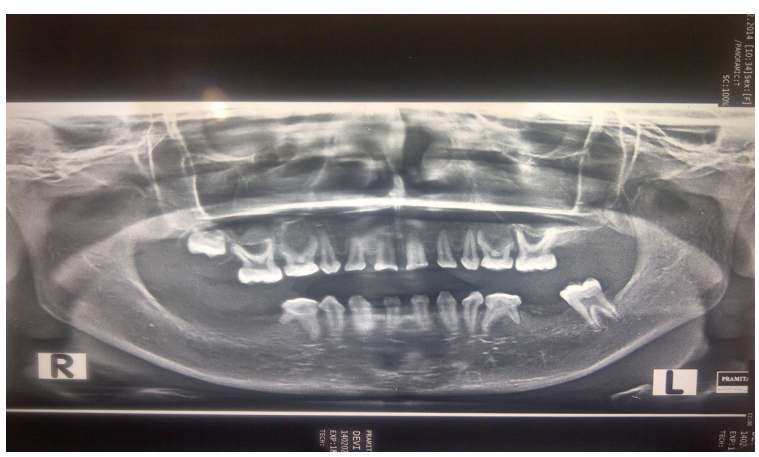

Gambar 3 Gambaran Radiologi Panoramik

health education, oral hyegine instruction, dan aplikasi topikal fluor. Perawatan restoratif berupa penambalan gigi 65, 74, dan 84 dengan bahan tambal komposit. Perawatan rehabilitatif berupa pembuatan mahkota akrilik pada gigi anterior rahang atas dan bawah, kemudian dibuat gigi tiruan lepasan sebagian kombinasi frame dan valplast untuk mengganti gigi 75 dan 85 yang hilang. Pemilihan pembuatan mahkota akrilik dikarenakan untuk mendapatkan retensi yang maksimal dan mengembalikan estetik.

Setelah berdiskusi dengan orangtua pasien mengenai perawatan yang akan dilaksanakan serta informed consent maka dimulai tahapan pembuatan protesa sebagai berikut: pencetakan rahang atas dan bawah yang dilanjutkan dengan pembuatan model studi; preparasi gigi 53,52 , $51,61,62,63,73,72,71,81,82,83$ (Gambar 4); pencetakan rahang atas dan bawah untuk model kerja; pembuatan model lilin mahkota akrilik dan gigi tiruan sebagian lepasan valplast pada model kerja (Gambar 5).

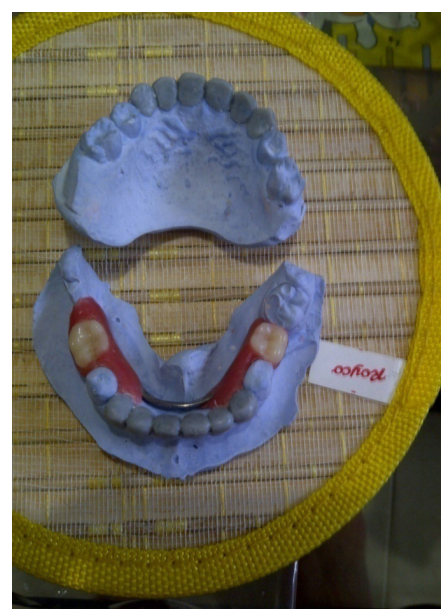

Gambar 5 Model Lilin 


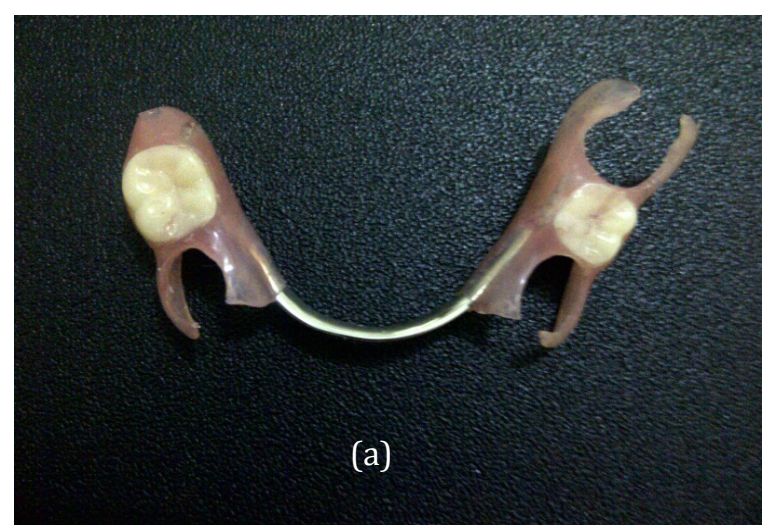

Gambar 6 Protesa (a) GTLS Valplast Rahang Bawah (b) Insersi Mahkota Akrilik

Uji coba model lilin terhadap pasien adalah pemasangan mahkota akrilik dan juga gigi tiruan lepasan sebagian valplast pada pasien (Gambar 6)

Setelah insersi gigi tiruan mahkota akrilik dan juga gigi tiruan sebagian lepasan valplast, pasien diberikan pembelajaran cara merawat gigi tiruan sebagian lepasan valplast dan selalu membersihkan gigi mahkota akrilik (gigi aslinya). Pasien disarankan kontrol dua minggu pertama untuk menilai adaptasi mahkota akrilik dan juga gigi tiruan sebagian lepasan. Kemudian, kontrol 1, 3, dan 6 bulan ke depan untuk memonitor pertumbuhan rahang serta re-lining gigi tiruan lepasannya.

\section{Pembahasan}

Pada anak yang menderita sindrom ED biasanya pertumbuhan tulang sedikit terganggu, hal ini disebabkan oleh salah satunya tidak terdapat benih gigi yang dapat merangsang pertumbuhan tulang rahang. ${ }^{5}$ Banyak penelitian pada pasien ED dengan oligodontia yang menyatakan bahwa pembuatan gigi palsu dengan mempertahankan gigi alami lebih baik apabila dibanding dengan pembuatan gigi palsu yang disertai ekstraksi pada gigi sulungnya. Gigi alami tahan dalam tekanan pengunyahan, mengurangi tekanan pada rahang, dan juga membantu mempertahankan tulang. ${ }^{10}$ Temuan klinis gigi pada pasien ED dapat berupa anodontia atau lebih umum hipodonsia gigi sulung atau gigi permanen. ${ }^{11}$ Sering kali gigi yang tumbuh memiliki mahkota berbentuk kerucut (conus). ${ }^{12}$ Pada kasus tersebut pasien masih memiliki gigi sulung berbentuk conus dengan akar yang baik sehingga dipertahankan

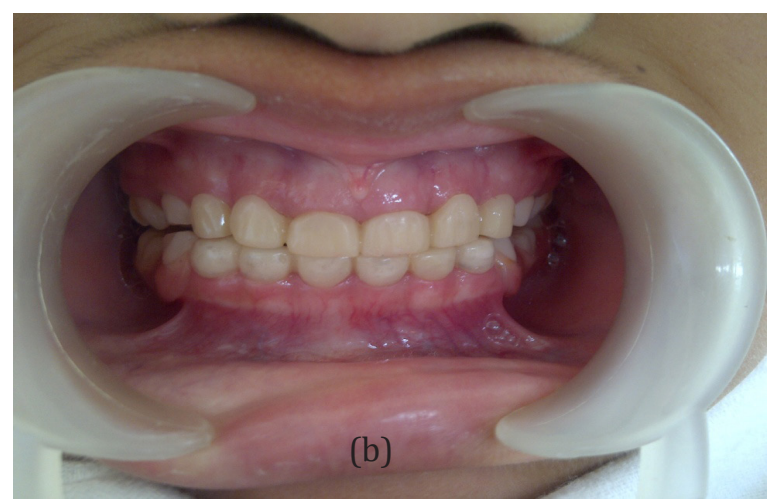

dan dibuat mahkota akrilik.

Alasan pemilihan penggunaan suatu mahkota akrilik pada gigi anterior rahang atas dan rahang bawah pada pasien ini adalah pembuatan yang relatif mudah, tidak berat, mudah direhabilitasi, dan dapat memenuhi nilai estetika yang baik. Alasan lainnya yaitu, pasien ini berusia 14 tahun dan sudah mengalami menstruasi sejak usia 12 tahun. Pertumbuhan serta perkembangan anak perempuan saat mengalami menstruasi sudah mencapai puncak dan selanjutnya akan melambat termasuk pada pertumbuhan dan perkembangan dentofacial sehingga pembuatan mahkota akrilik pada gigi anterior rahang atas dan bawah tidak akan berpengaruh besar pada pertumbuhan dan perkembangan rahang. ${ }^{13}$

Pembuatan gigi tiruan dianjurkan untuk anak dengan kehilangan gigi (alami atau prematur) untuk membantu mengurangi mobilitas gigi yang tersisa dan membantu mencegah resorbsi tulang. ${ }^{10}$ Untuk pasien anak penggunaan gigi tiruan sebagian lepasan (RPD) adalah perawatan yang signifikan dapat meningkatkan fungsi dan estetika tanpa membahayakan gigi geliginya. ${ }^{6}$ Berbagai jenis gigi palsu lepasan banyak tersedia. Penggunaan bahan termoplastik seperti valplast telah meningkat secara drastis dalam dekade akhir. Gigi palsu valplast mempunyai berbagai keunggulan dibanding dengan basis gigi tiruan konvensional (berbahan dasar akrilik). ${ }^{14}$ Bahan ini sangat kuat dan fleksibel. Biokompatibilitas dicapai dengan baik karena materi bebas dari monomer dan logam tidak menyebabkan reaksi alergi.

Pada kasus tersebut, pasien sangat kooperatif dan mempunyai motivasi yang kuat untuk dapat memperbaiki penampilan atau estetika serta fungsi pengunyahannya. Keadaan itu mampu 
mengakibatkan pasien tersebut menjadi lebih mudah untuk menerima dan menyesuaikan diri dengan alat protesa yang digunakannya. ${ }^{15}$

Setelah dilakukan perawatan, pasien merasa senang dan nyaman dengan mahkota akrilik dan gigi tiruan sebagian valplast karena ringan dan cukup puas dengan estetika karena tidak terdapat logam yang biasanya terlihat di gigi palsu parsial lainnya. Dilaporkan perbaikan dalam hal estetik dan pengunyahan pada pasien ini.

Sindrom ED merupakan kelainan genetik yang jarang terjadi dengan kelainan pada struktur ektodermal berupa kelainan di kulit, kuku, kelenjar keringat, dan kuku. Kelainan ini lebih sering didapatkan pada laki-laki. Berbagai variasi dapat terjadi sebagai gambaran ED maka dokter gigi harus memikirkan ED sebagai salah satu etiologi pada setiap pasien dengan kelainan bentuk, struktur, atau jumlah gigi. Perawatan terhadap kelainan bentuk dan hilangnya gigigeligi secara kongenital yang berhubungan dengan kelainan ED dapat dilakukan dengan pembuatan gigi tiruan, baik lepasan maupun cekat. Pembuatan gigi tiruan ini harus dapat mengembalikan atau juga memperbaiki fungsi pengunyahan, bicara, disamping estetik. Selain itu, pembuatan gigi tiruan pada anak harus mempertimbangkan aspek tumbuh kembang anak.

Kekurangan kami sebagai dokter gigi adalah kami belum merujuk ke ahli genetika untuk lebih memastikan anak tersebut memiliki kelainan ED karena keterbatasan biaya dan tempat tinggal pasien yang jauh dari Kota Bandung. Oleh karena itu, kami menyarankan untuk pemeriksaan lebih lanjut sehingga diagnosis dapat ditegakkan.

Simpulan perawatan anak ED pada laporan kasus ini, berupa perbaikan fungsi estetik dan pengunyahan dengan dibuatkan gigi palsu cekat pada enam gigi anterior rahang atas dan bawah serta gigi palsu lepasan pada gigi posterior rahang bawah sehingga estetika, pengunyahan, dan pemeliharaan pertumbuhan rahang dapat terjaga serta berlangsung baik.

\section{Daftar Pustaka}

1. Alcan T, Basa S, Kargul B. Growth analysis of a patient with ectodermal dysplasia treated with endosseous implant: 6-years follow-up. J Oral Rehabil. 2006;33(3):175-82.

2. DellaValleD, ChevitareseAB,MaiaLC,Farinhas JA. Alternative rehabilitation treatment for a patient with ectodermal dysplasia. J Clin Pediatr Dent. 2004;28(2):103-6.
3. Aldred MJ, Crawford PJM, Cameron A, King NM, Widmer R. Dental anomalies. Dalam: Cameron AC, Widmer R, penyunting. Handbook of pediatric dentistry. Edisi ke-3. Sydney: Mosby, 2008. hlm. 186-90.

4. Clarke A. Features of ectodermal dysplasia:dominance, sex and women [Online Journal] 2014 [diunduh 11 Agustus 2014]. Tersedia dari: http://www. ectodermaldysplasia.org.

5. Dean JA, Mc. Donald RE, Avery DR, penyunting. Dentistry for the child and adolelescent. Edisi ke-9. Indianapolis: Mosby; 2011.

6. Jain N, Naitam D, Wadkar A, Nemane A, Katoch S, Dewangan A. Prosthodontic rehabilitation of hereditary ectodermal dysplasia in an 11-year-old patient with flexible denture: a case report. Case Rep Dent. 2012;22:1-5.

7. Crawford PJM, Aldred MJ. Anomalies of tooth formation and eruption. Dalam: Welbury R, Duggal MS, Hosey MT, penyunting. Paediatric dentistry. Edisi ke-4. New York: Oxford Univ. Press; 2012. hlm. 253-74.

8. Rani TS, Reddy RE, Manjula M, Sreelakshmi N. Prosthetic rehabilitation of a 7 year old child with hypohidrotic ectodermal dysplasia. IJDA. 2009;1(1):56-9.

9. Lukes S, Sherry JS, penyunting. Hypohidrotic ectodermal dysplasia. American Dental Association Continuing Education Recognition Program; November 2010; East Chicago: ADA CERP; 2010.

10. Division of Health Care Finance and Policy, Commonwealth of Massachusetts. Review and evaluation of proposed legislation to mandate coverage for ectodermal dysplasia: Senate Bill 837. Massachusetts: The State Library of Massachusetts; 2005.

11. Willyanti S, Syarief H. Erupsi gigi sulung pada anak dengan riwayat lahir prematur. MKB. 201;46(1):34-8.

12. Sholapurkar AA, Setty S, Pai KM. Total anodontia in patient with hypohidrotic ectodermal dysplasia. Report of rare case of Christ-Siemens Touraine syndrome. NY State Dent J. 2011;77(1):36-9.

13. Gillgrass T], Welbury R. Craniofacial growth and development. Dalam: Welbury R, Duggal MS, Hosey MT, penyunting. Paediatric dentistry. Edisi ke-4. New York: Oxford Univ. Press; 2012. hlm. 1-16.

14. Shamnur SN, Jagadeesh KN, Kalavathi SD, Kashinath KR. "Flexible dentures"-an alternate for rigid dentures?. J Dental Sci Research. 2010;1(1):74-9.

15. Mopagar V, Naik S, Jadhav RG, Raurale A. 
Anie Apriani: Penatalaksanaan Oligodontia pada Anak 14 Tahun dengan Sindrom Ectodermal Dysplasia: Laporan Kasus

Complete denture prostheses in an 8-yearold child with hypohidrotic ectodermal dysplasia: case report. J Pediatr Dent. 2014; 2(2):74-7. 